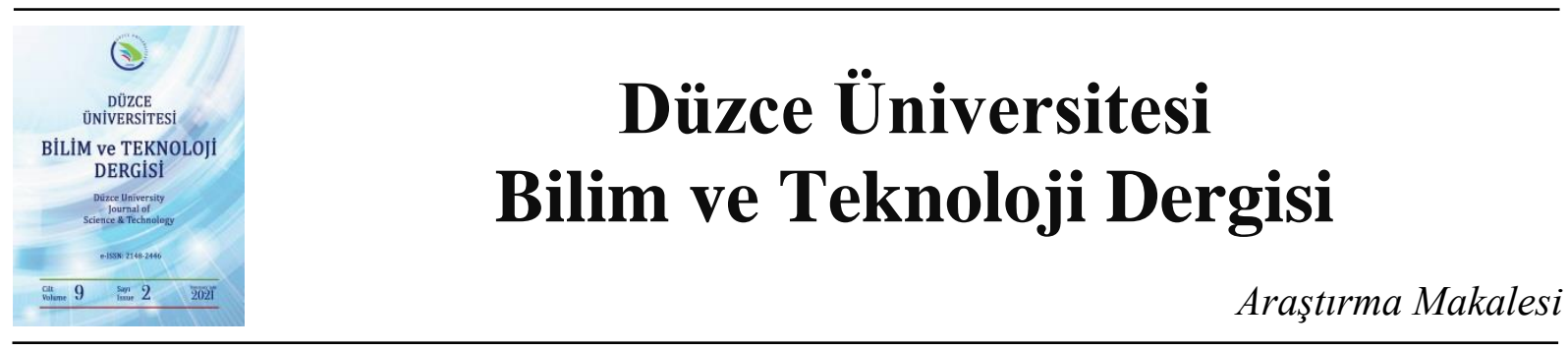

\section{AHSS Sacların Elektrik Direnç Nokta Kaynağında Kaynak Parametrelerinin Taguchi Yöntemiyle Optimizasyonu}

\author{
Melih KEKİ ${ }^{\mathrm{a}, *}$, (D) Salim ASLANLAR ${ }^{\mathrm{a}}$, (DSerkan APAY ${ }^{\mathrm{b} *}$ \\ ${ }^{a}$ Metalurji Müh. Bölümü, Lisansüstü Eğt. Enst, Sakarya Uygulamalı Bilimler Üniversitesi, Sakarya, TÜRKIYYE \\ ${ }^{\mathrm{b}}$ Makine Müh. Bölümü, Mühendislik Fakültesi, Düzce Üniversitesi, Düzce, TÜRKİYE \\ * Sorumlu yazarin e-posta adresi serkanapay@duzce.edu.tr
}

DOI: $10.29130 /$ dubited.837588

\section{ÖZET}

Malzeme teknolojilerinin gelişimi ile birlikte AHSS (Advanced-High Strength Steel) adı verilen üçüncü nesil geliştirilmiş yüksek gerilimli saclar can güvenliği amacıyla otomotiv imalatında sıklıkla kullanılmaktadır. Şase, kapı takviye sacı ve direk imalatında kullanılan bu sacların birleştirilmesi genellikle elektrik direnç nokta kaynağı ile yapılmaktadır. Elektrik direnç kaynağı, otomotiv imalat sektöründe robot kullanarak otomatikleşme ve seri üretime olanak sağlaması nedeniyle önemli bir yer tutmaktadır. Bir diğer önemli nokta ise kaynaklı birleştirme esnasında kaynak kalitesini etkileyen kaynak parametreleridir. Elektrot baskı kuvveti, kaynak için harcanan süre ve kaynağın gerçekleştirileceği akım değeri parametreleri elektrik direnç kaynağı için oldukça önemlidir. Bu çalışmada, $1200 \mathrm{M}$ ve DP800HF AHSS sacların elektrik direnç kaynağında kullanılan kaynak akımı, kaynak zamanı ve kaynak çene baskı kuvvetlerinin nokta çekirdeği (kaynak dikişi) sertliği üzerine etkisinin, Taguchi yöntemiyle optimize değerleri incelenmiştir. Optimizasyon uygulamasında kullanılan Taguchi metodunda $\mathrm{L}_{18}$ ortagonal serisi kullanılmıştır. Bu seri ile birlikte optimizasyon sonuçlarının kontrol edilmesinde sinyal/gürültü $(\mathrm{S} / \mathrm{N})$ oranı belirleyici olmuştur. Deneysel çalışmalar ve optimizasyon işlemi sonuçları incelendiğinde gerçek uygulama ve Taguchi optimizasyonu ile yapılan analizden elde edilen sertlik sonuçlarının birbirine yakın olduğu görülmüştür.

Anahtar Kelimeler: AHSS çelik sac, Elektrik direnç nokta kaynă̆l, Sertlik, Taguchi metodu.

\section{Optimization of Welding Parameters of AHSS Sheet Metals in Electric Resistance Spot Welding by Taguchi Method}

\footnotetext{
ABSTRACT

With the development of material technologies, the third-generation high tensile sheets called AHSS (AdvancedHigh Strength Steel) are frequently used in automotive manufacturing for life safety. The joining of these sheets used in chassis, door reinforcement sheet and pole manufacturing is usually done by electrical resistance point welding. Electric resistance welding has an important place in the automotive manufacturing sector, as it enables automation and mass production using robots. Another important point is the welding parameters that affect the welding quality during the welded joint. Electrode pressure force, time spent for welding and current value parameters where welding will be performed are very important for electrical resistance welding. In this study, the effect of welding current, welding time and welding jaw pressure forces on the point core (weld seam) hardness, which are used in electrical resistance welding of $1200 \mathrm{M}$ and DP800HF AHSS sheets, were investigated by Taguchi method. Optimization values were analysed with Taguchi method. $\mathrm{L}_{18}$ orthogonal series is used in Taguchi method used in optimization application. With this series, the signal / noise ( $\mathrm{S} / \mathrm{N})$ ratio was decisive in controlling the optimization results. When the experimental studies and the results of the optimization process were examined, it was seen that the hardness results obtained from the analysis performed by real application and Taguchi optimization were close to each other.
} 
Geliş: 08/12/2020, Düzeltme: 08/01/2021, Kabul: 18/01/2021

\section{GIRIS}

Yeni nesil araçlarda yolcu ve taşıt güvenliği amacıyla karoser üzerinde giderek daha fazla noktada tercih edilen AHSS grubu çeliklerin birleştirilmesinde en fazla uygulanan yöntem elektrik direnç nokta kaynağıdır. Gelişen otomotiv teknolojileri ile birlikte giderek yükselen mukavemetle daha ince çelik saçların araçların karoserinde kullanılmasıyla araçlar ağrılıkları azalmış ve bu araçlarda kullanılan yakıttan tasarruf sağlanmış olup karbon salınımı gibi çevresel etmenlerde iyileşme sağlanmıştır. Araçların ağırlıklarının azaltılması amacıyla alternatif çelik ürünlerin kullanımı deneysel amaçlardan çıkıp imalat aşamasına geçmiştir. Yüksek mukavemetli çeliklerin kullanımı ile taşıt hafifletme çalışmaları önemli yollar kat etmiştir. AHSS çeliği araç parçalarında güvenlik ve güç sağlarken, ağırlıklarını azaltarak yakıt verimliliğini artırmak için kullanılmaktadır. Araç ağırlığının azaltılması, mevcut durumdaki parçaların dayanım ve performanslarını arttırıp daha da ince yüksek mukavemetli çeliklerin kullanılmasıyla gerçekleşmektedir. Bunlarla birlikte yüksek mukavemet, yüksek şekil kabiliyeti ve hafif olmaları sebebiyle Dual Phase (DP) ve Martenzit çeliklerinin kullanım alanı giderek yaygınlaşmışıtır [1]-[3]. Otomotiv endüstrisinde en sık kullanılan iki AHSS, çift fazlı (DP) çelik ve dönüşüm kaynaklı plastisite (TRIP) çeliğidir [4], [5]. Geliştirilmiş yüksek mukavemetli çelikler arasında yer alan Martenzitik çelik yüksek kaynak kabiliyeti ve üstün şekillenebilirliği ile DP çeliğiyle yakın özellikleri sebebiyle kaynaklanmasında ve birlikte kullanılmasında herhangi bir sorunla karşılaşılmamıştır [6]-[9].

Otomotiv endüstrisinde en çok kullanılan kaynak yöntemi elektrik nokta direnç (RSW) kaynağıdır. Bu yöntemin diğer yöntemlere göre birçok avantajı vardır. Örnek olarak, kaynak hızlı bir şekilde yapılabilir, seri üretime uygun olabilir ve diğer kaynak yöntemlerine kıyasla daha ucuz olabilir. Bugün, bir aracın imalatında yaklaşık 2000 - 5000 arasında nokta direnç kaynağı ile birleştirme yapılmaktadır. $\mathrm{Bu}$ miktar, elektrik nokta direnç kaynağının önemini göstermektedir. Elektrotların uyguladığı basınç ve elektrik direncinin ürettiği 1sı, elektrotlar ve levhalardan geçerek kaynak işlemini yani birleşmeyi gerçekleştirmiş olur [10]-[12]. Gaz tungsten ark nokta, lazer nokta ve sürtünme karıştırma nokta kaynağı gibi farklı teknolojiler olmasına rağmen, geleneksel nokta direnç kaynağı, özellikle otomotiv endüstrisinde sac metal birleştirmede hala yoğun olarak kullanılmaktadır [13], [14]. İşlem sırasında elektrik enerjisi iletimi ve kontrolü çok önemlidir. Kaynak sistemi, geleneksel bir ana güç kaynağı tarafından beslenir ve bu kaynak düşük voltajlı yüksek akım gücüne sahiptir. Elektrik direnç nokta kaynak makineleri, tek fazlı alternatif akım ve üç faz orta frekanslı doğru akım olmak üzere iki tiptir. Tek fazlı alternatif akım elektrik direnç nokta kaynak makinesi diğerine göre daha uygun maliyetli ve daha basit bir çalışma sistemine sahiptir. Üç fazlı bir orta frekanslı DC RSW makinesi sürekli olarak enerji sağlayabilir ve daha yüksek verimlilikte çalıştırılabilir ve karmaşık bir yapıya sahiptir. AC güç kaynağı tarafından belirlenen sabit ve düşük bir çalışma frekansına sahip olan tek fazlı AC RSW makinesine kıyasla, üç fazlı orta frekanslı DC RSW makinesinin çıkışı ve kontrol frekans1 ayarlanabilir. Bu nedenle, son zamanlarda, orta frekanslı DC RSW makinesi giderek daha fazla tercih edilmekte ve tek fazlı AC RSW makinesinin yerini almıştır [15]-[19]. Otomotiv sektöründe RSW ile kaynakta yüksek kaliteli nokta kaynak bağlantıları oluşturmanın yolu, gerilim, kaynak akımı, elektrot basıncı, zaman, yüzey durumları gibi kaynak parametrelerini kontrol altında tutmaktan geçmektedir [20].

Taguchi optimizasyon yöntemi, mühendislik uygulamaları için, ürün kalitesini arttırma, tasarım becerilerini iyileştirme ve deney sayısını azaltmaya yarayan istatistiksel bir analiz uygulamadır. Deneysel çalışma sayını azaltması ve deneysel tasarımı iyileştirmesi bu uygulamanın fazla tercih edilmesine neden olmaktadır. Mühendislik olarak çok karmaşık yapılara sahip ürünler bile bu uygulama ile yüksek hızlarda ve uygun maliyetlerde üretilebilmektedir. Yapılacak olan işleme ait deneysel parametrelerin optimize edilmesi, üretim maliyetlerini olumlu yönde etkileyerek kaliteli ürün üretmeyi mümkün kılmada Taguchi optimizasyon yöntemi oldukça önemli bir adımdır [21]. Bu optimizasyon uygulamasının önemli bir yanı da çalışma ya da üretim sonucunda elde edilecek üründen 
beklenen çıktı değere en yakın kalitede ve uygunlukta ürün gerçekleştirilebilmesine imkân sağlamasıdır. İmalat proses parametrelerinin sayısı arttı̆̆ında sonuca ulaşabilme adına çok sayıda deney yapılması gerekir. Bu gerekliliği çözebilmek adına Taguchi yöntemi, az sayıda deneyle tüm işlem parametresi alanını incelemek için özel bir ortagonal diziler tasarımı kullanabilmektedir. $\mathrm{Bu}$ ortagonal dizi tasarımını kullanarak tasarımcı, deneysel verileri analiz etmek için bir sinyal-gürültü (S/N) oranı kullanıp, ortalama kalite özellikleri ve varyasyonları üzerindeki birden çok parametreyi kontrol ederek imalata en uygun parametre kombinasyonların kolayca tespit edebilmektedir. $\mathrm{Bu}$ nedenle, deneysel çalışmada kullanılan parametrelerin optimize seviyeleri sinyal-gürültü seviyelerine göre değişmektedir. Diğer yandan deneysel çalışmadaki parametrelerin önem sıralamasını belirlemede istatistiksel bir metot olan varyans analizi (ANOVA) uygulamas1 yapılmaktadır. ANOVA parametrelerin güvenilirlik aralığını belirler ve en önemli olandan en az önemli olana doğru yüzdelik oranla sonuç bildirir. Taguchi optimizasyonu sonucu istenen değere en yakın değerlerde, deneysel çalışma gerçekleştirilerek (doğrulama testi) deneysel çalışmanın istenen sonucu verip vermediği doğrulanabilir [21]-[23].

Deneysel çalışmalardan önce gerçekleştirilen literatür taramasında, elektrik direnç kaynağı uygulamalarında birçok optimizasyon uygulamalarının yapıldığı görülmüştür. Genelinde farklı sonuçların optimizasyonunun gerçekleştirildiği tespit edilmiştir. Optimize bir işlem için kaynak parametrelerini seçmek, kaynak mukavemeti, kaynak kalitesi ve verimlilik arasındaki ilişkiyi kurmak için ayrıntılı bir inceleme çalışması yapılmıştır. Esme [21], Taguchi yöntemini kullanarak çelik sacların direnç punta kaynağı işleminde kaynak performansını artırmak ve kaynak parametrelerini optimize etmek için kullanılan Taguchi yönteminin uygunluğunu tespit etmiştir. Luo ve arkadaşları [24], elektrik direnç kaynağı ile galvaniz kaplı çeliklerin birleştirilmesinde, deneysel parametrelerin kaynak çekirdeği kalitesine etkilerini, varyans analizi ve geliştirdikleri matematiksel modeli kullanarak en iyi sonuç için tahmin modeli gerçekleştirmişlerdir. Vural ve Akkuş [25], östenitik paslanmaz çelik saclara sahip galvanizli ara boşluksuz çelik sacların direnç nokta kaynaklanabilirliğini araştırmış ve kaliteli kaynak için optimum parametreleri tespit etmişlerdir.

Bu çalışmada, optimum sertlik değerleri ile kaynak proses parametrelerini belirlemek için Taguchi yönteminin kullanılmıştır. Deneysel sonuçlar, direnç punta kaynağı işleminde kaynak performansını artırmak ve kaynak parametrelerini optimize etmek için kullanılan Taguchi yönteminin geçerliliğini doğrulamıştır.

\section{DENEYSEL CALISMALAR}

Otomotiv sektöründe kullanılan DP800HF ve 1200M sacları elektrik direnç nokta kaynağ 1 ile birleştirilmiştir. Yapılan birleştirme işlemlerinde sıkıştırma ile tutma süreleri sabit tutularak, elektrot kuvveti, kaynak akım şiddeti ve kaynak zamanı değiştirilmiştir. Kullanılan her parametre için mikroyapı incelemesi ve mikro sertlik ölçümü testleri uygulanmıştır. Deneysel çalışmada kullanılan sacların kimyasal içerikleri Tablo 1'de verilmiştir.

Tablo 1. Deneysel çalışmada kullanılan sacların kimyasal bileşimi (\% ă̆ırlık)

\begin{tabular}{cccccccccc}
\hline Malzeme & $\mathbf{C}$ & $\mathbf{S i}$ & $\mathbf{M n}$ & $\mathbf{P}$ & $\mathbf{S}$ & $\mathbf{A l}$ & $\mathbf{C r}$ & Mo & Co \\
\hline DP800 & 0.16 & 0.5 & 2.2 & 0.015 & 0.005 & 0.7 & 0.45 & - & - \\
\hline $\mathbf{1 2 0 0 M}$ & 0,0791 & 0.201 & 1.6 & 0.00037 & 0.00022 & 0.0363 & 0.0175 & 0.0373 & 0.0133 \\
\hline
\end{tabular}




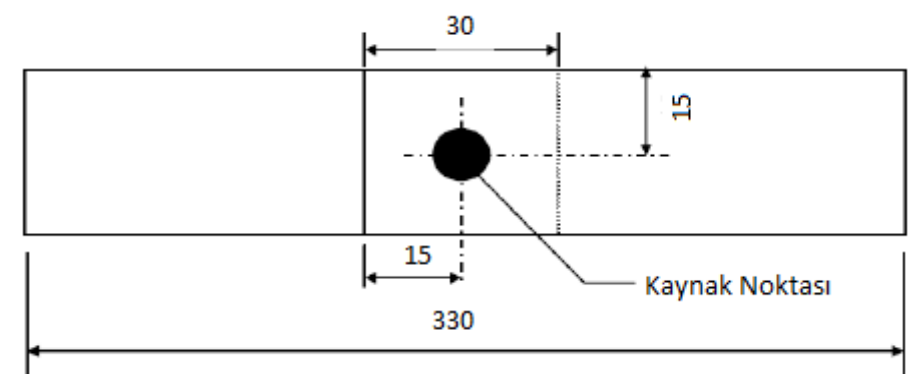

Şekil 1. Elektrik nokta direnç kaynă̆ı deney numunesi şematik ölçüleri.

Deney numuneleri Şekil 1'de örnek olarak gösterilen boyutlarda hazırlandıktan sonra gerekli yüzey temizlikleri yapılarak elektrik direnç nokta kaynak yöntemi ile birleştirilmeleri yapılmıştır. Deney numunelerinin hepsinde $4-6 \mathrm{kN}$ elektrot kuvveti uygulanmıştır. Kaynak süreleri ön deneyler sonucunda 5,15 ve 25 periyot ( 1 periyot kaynak süresi $=0,02 \mathrm{sn}$ ) belirlenmiştir. Kaynak akımı için 8 , 11 ve $15 \mathrm{kA}$ (8440A- 15500A aralığında) uygulanarak kaynak işlemi tamamlanmıştır. Deneysel çalışmalar sonucu elde edilen numuneler bakalite alınıp metalografik süreçler sonrasında elde edilmiş numunelerin \%2'lik nital çözeltisi ile dağlanarak mikroyapı görüntüleri alınacak şekilde hazırlanmış ve mikro sertlik ölçümü için hazır hale getirilmiştir. Kaynak parametrelerinin sertlik üzerindeki etkisini incelemek üzere elde edilmiş olan her numunenin sertlik değerleri BORÇELIK Ar-Ge merkezindeki EmcoTest DuraScan marka seri mikro sertlik ölçme cihazıyla ölçülmüştür. Mikro sertlik ölçümleri $\mathrm{HV}_{0,2}$ ile 200 gr yük uygulanarak, 10 sn süre zarfinda konik uçlu batıcı ucun numune üzerine batmasıyla ölçülmüş olup değerler Vickers cinsinden bulunmuştur. Kaynak bölgesinde iki farklı malzeme bulunduğu için çekirdek bölgesinin sol üst kısmından başlamak üzere sağ alt kısmına doğru çapraz bir yol izlenerek Şekil 2'de verildiği gibi 0,4 mikron aralıklarla alınmıştır. Yapılan ölçümler sonucunda tek çizgi hattında toplam 50 sertlik ölçüm yapılmış olup çizgi boyunca yapılan sertlik ölçümünün ortalama değeri nominal sertlik değeri olarak hesaplanıp Taguchi deney tasarımına sonuç verisi olarak girilmiştir.

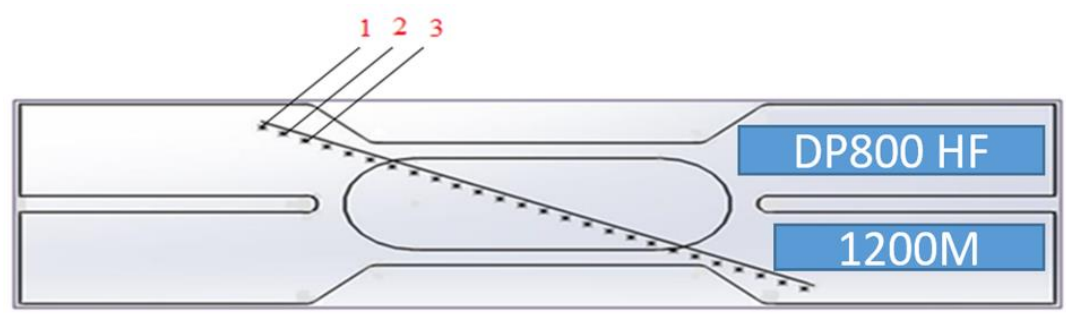

Şekil 2. DP800HF-1200M birleştirmelerindeki sertlik ölçümü şematik gösterimi.

Doğru deney tasarımının kurulması, deneysel çalışmalarda elde edilecek sonuçların doğruluğu için önem arz etmektedir. Elektrolitik yöntemle sert krom kaplamanın gerçekleştirildiği bu çalışmada, deneysel düzenek ve sonuç analiz yöntemi olarak Taguchi $\mathrm{L}_{18}$ ortagonal dizin kullanılmıştır. $\mathrm{Bu}$ yaklaşımda, deneysel çalışma verilerinin analizi için Sinyal-gürültü $(\mathrm{S} / \mathrm{N})$ oranı olarak bilinen bir istatistiksel analiz yöntemi kullanılmaktadır. Bu sinyal/gürültü oranı, deneysel süreçteki değişkenleri azaltan kontrol faktörlerini Taguchi optimizasyon uygulamasında en aza indirerek, optimizasyon işlemi için doğrulama değeridir. Taguchi yöntemiyle tasarlanmış bir deneyde, değişkenliği gerçekleştirmek ve sonuçlardan süreci veya ürünü gürültü faktörlerinden kaynaklanan değişikliklere dirençli hale getiren optimum kontrol faktörü ayarlarını tanımlamak için gürültü faktörlerini değiştirerek gerekli düzenleme sağlamaktadır. Gürültü faktörlerini en aza indirerek, sinyal-gürültü oranı için en yüksek değerler ayarlanabilir. Sinyal-gürültü oranı, farklı oranlardaki gürültü değerlerinin optimum koşullarda vereceği tepkiyi veya istenen değerlere göre nasıl değişmesi gerektiğini belirleyebilir. Deneysel çalışmanın amacına bağlı olarak farklı sinyal-gürültü oranları arasından seçim yapılarak sonuca ulaşılabilmektedir. Sinyal-gürültü oranlarını etkilemeden hedef üzerindeki ortalamayı ayarlamak için ölçeklendirme faktörleri kullanılabilir. Optimizasyon işlemlerinde kullanılan 
yazılımlar, tasarımdaki her bir kontrol faktörü seviyesi kombinasyonu için ayrı bir sinyal-gürültü $(\mathrm{S} / \mathrm{N})$ oranı hesaplar. Taguchi optimizasyonuna bağlı olarak istenen deneysel sonuç verilerini elde edebilmek için, parametrelere bağlı olarak farklı sinyal-gürültü oranları arasında seçim yapılması gerekmektedir. Bu seçimle birlikte deneysel çalışma sonucunda istenen değere en yakın tahmin değerleri elde edilebilir. Optimizasyon işlemi için seçilecek $\mathrm{S} / \mathrm{N}$ oranları, daha küçük daha iyidir, daha büyük daha iyidir ve nominal olan en iyidir şeklinde değişiklik göstermektedir [26], [27]. Bu çalışma, kalite karakteristiği olarak ele alınan kaplama sertlik değerinin yüksek olması arzu edildiğinden $\mathrm{S} / \mathrm{N}$ oranlarının hesaplanmasında "en büyük en iyi" yaklaşımı dikkate alınmıştır. S/N oranlarının hesaplanmasında eşitlik l'de verilen denklem kullanılmıştır. Burada; "yi”" ölçülen sertlik değerini, "i" gözlem değerini, " $n$ " bu çalışma için geçerli deneyleri ifade etmektedir.

$S / N=-10 \log \left(\frac{1}{n} \sum_{i=1}^{n} \frac{1}{y_{i}^{2}}\right)$

DP800HF ve 1200M sacları birbirlerine elektrik direnç nokta kaynağı ile birleştirilmesinde kontrol faktörleri ve seviyeleri Tablo 2'de verilmiştir.

Tablo 2. Kontrol faktörleri ve seviyeleri

\begin{tabular}{clccc}
\hline Sembol & Kontrol Faktörleri & Seviye 1 & Seviye 2 & Seviye 3 \\
\hline A & Elektrot kuvveti (kN ) & 4 & 6 & - \\
\hline B & Kaynak akım şiddeti $(\mathrm{kA})$ & 8 & 11 & 15 \\
\hline C & Kaynak zamanı (çevrim $)$ & 5 & 15 & 25 \\
\hline 1 çevrim $=0,02 \mathrm{sn}$ & & &
\end{tabular}

\section{BULGULAR VE TARTIȘMA}

\section{A. KAYNAK DİKİSi SERTLİĞİ OPTIMMIZASYONU}

DP800HF ve 1200M sacları birbirlerine elektrik direnç nokta kaynağı ile birleştirilmesinin Taguchi $\mathrm{L}_{18}$ deneysel tasarımına göre gerçekleştirilen optimizasyon deneyi sertlik sonuçları ve hesaplanan $\mathrm{S} / \mathrm{N}$ oranları tahmin değerleri Tablo 3'de verilmiştir.

Tablo 3. Deney tasarımı, sertlik ve S/N oranlart

\begin{tabular}{ccccccc}
\hline No & $\begin{array}{c}\text { Elektrot } \\
\text { kuvveti } \\
(\mathbf{k N})\end{array}$ & $\begin{array}{c}(\mathbf{B}) \\
\text { Kaynak } \\
\text { akımı } \\
(\mathbf{k A})\end{array}$ & $\begin{array}{c}\mathbf{( C )} \\
\text { Kaynak } \\
\text { zamanı } \\
(\text { Çevrim) }\end{array}$ & $\begin{array}{c}\text { Sertlik } \\
\left(\mathbf{H V}_{\mathbf{0 . 2}}\right)\end{array}$ & $\begin{array}{c}\text { S/N Oranı } \\
(\mathbf{d B})\end{array}$ & $\begin{array}{c}\text { Tahmin Edilen } \\
\text { Sertlik Degeri } \\
\left(\mathbf{H V}_{\mathbf{0 . 2}}\right)\end{array}$ \\
\hline 1. & 4 & 8 & 5 & 444,3 & 52,9535 & 444,353 \\
\hline 2. & 4 & 8 & 15 & 421,5 & 52,4960 & 423,635 \\
\hline 3. & 4 & 8 & 25 & 417,56 & 52,4144 & 413,670 \\
\hline 4. & 4 & 11 & 5 & 439,86 & 52,8663 & 435,573 \\
\hline 5. & 4 & 11 & 15 & 412,16 & 52,3013 & 414,855 \\
\hline 6. & 4 & 11 & 25 & 404,86 & 52,1461 & 404,890 \\
\hline 7. & 4 & 15 & 5 & 433,12 & 52,7322 & 429,582 \\
\hline 8. & 4 & 15 & 15 & 403,94 & 52,1263 & 408,863 \\
\hline 9. & 4 & 15 & 25 & 397,02 & 51,9762 & 398,898 \\
\hline 10. & 6 & 8 & 5 & 481,42 & 53,6505 & 481,821 \\
\hline 11. & 6 & 8 & 15 & 463,11 & 53,3137 & 461,103 \\
\hline 12. & 6 & 8 & 25 & 447,83 & 53,0223 & 451,138 \\
\hline 13. & 6 & 11 & 5 & 471,64 & 53,4722 & 473,041 \\
\hline
\end{tabular}




\begin{tabular}{ccccccc}
\hline 14. & 6 & 11 & 15 & 453,03 & 53,1225 & 452,323 \\
\hline 15. & 6 & 11 & 25 & 441,49 & 52,8984 & 442,358 \\
\hline 16. & 6 & 15 & 5 & 461,08 & 53,2755 & 467,049 \\
\hline 17. & 6 & 15 & 15 & 453,37 & 53,1291 & 446,331 \\
\hline 18. & 6 & 15 & 25 & 438,56 & 52,8406 & 436,366 \\
\hline
\end{tabular}

Taguchi optimizasyonunda her faktör için tanımlama ve yorumlama için $\mathrm{S} / \mathrm{N}$ yanıt tablosu vardır. $\mathrm{Bu}$ tablo en iyi seviye ve düzeyleri seçebilmek için referans sonuçları içermektedir. Deneysel çalışmalarda verilerin istenen sonucu ne şekilde etkilediği bu tablolar ile belirlenmektedir. Bu çalışmadaki parametrelerin sertlik özelliğini ne şekilde etkilediğini gösteren yanıt tablosu Tablo 4'de verilmiştir. Tablo 4'de görülen veriler incelendiğinde optimizasyon için seçilen en büyük en iyi opsiyonuna göre en yüksek değerler optimum sonuçları işaret etmektedir.

Tablo 4. Deney tasarımı, sertlik ve $S / N$ oranlarl

\begin{tabular}{cccc}
\hline Seviye & $\begin{array}{c}\text { (A) Elektrot } \\
\text { kuvveti }(\mathbf{k N})\end{array}$ & $\begin{array}{c}\text { (B) Kaynak akımı } \\
(\mathbf{k A})\end{array}$ & $\begin{array}{c}\text { (C) Kaynak zamanı } \\
\text { (Çevrim) }\end{array}$ \\
\hline 1 & 52,45 & $\mathbf{5 2 , 9 8}$ & $\mathbf{5 3 , 1 6}$ \\
\hline 2 & $\mathbf{5 3 , 1 9}$ & 52,80 & 52,75 \\
\hline 3 & & 52,68 & 52,55 \\
\hline Delta & 0,75 & 0,30 & 0,61 \\
\hline Siralama & 1 & 3 & 2 \\
\hline
\end{tabular}

Tablo 4'de verilen değerler dikkate alındığında, optimum kaplama sertliğine ait seviyeleri veren S/N oranları A2B1C1 olmuştur. Diğer bir ifadeyle elektrot kuvveti, kaynak akımı şiddeti ve kaynak zamanı için sırasıyla 53.19 (Seviye 1), 52.98 (Seviye 2) ve 53.16 (Seviye 3) optimum değerler olmuştur. Bu tablo seviye değerleri kullanılarak oluşturulan ana etki grafiği Şekil 3'de verilmiştir. Deney tasarımı, sertlik ve $\mathrm{S} / \mathrm{N}$ oranları tablosunda olduğu gibi Şekil 3'de verilen ana etki grafiğinde de en büyük S/N değerleri, elektrik direnç nokta kaynağında kullanılan parametrelere ait optimum seviyeleri göstermektedir. Bu değerlere göre DP800HF ve $1200 \mathrm{M}$ sacları birbirlerine elektrik direnç nokta kaynağı ile birleştirilmesinde, elektrot kuvveti, kaynak akımı şiddeti ve kaynak zamanı için sırasıyla optimum değerler $6 \mathrm{kN}, 8 \mathrm{kA}$ değerinde ve 5 çevrim zaman değerinde yapılan işlem olarak belirlenmiştir.

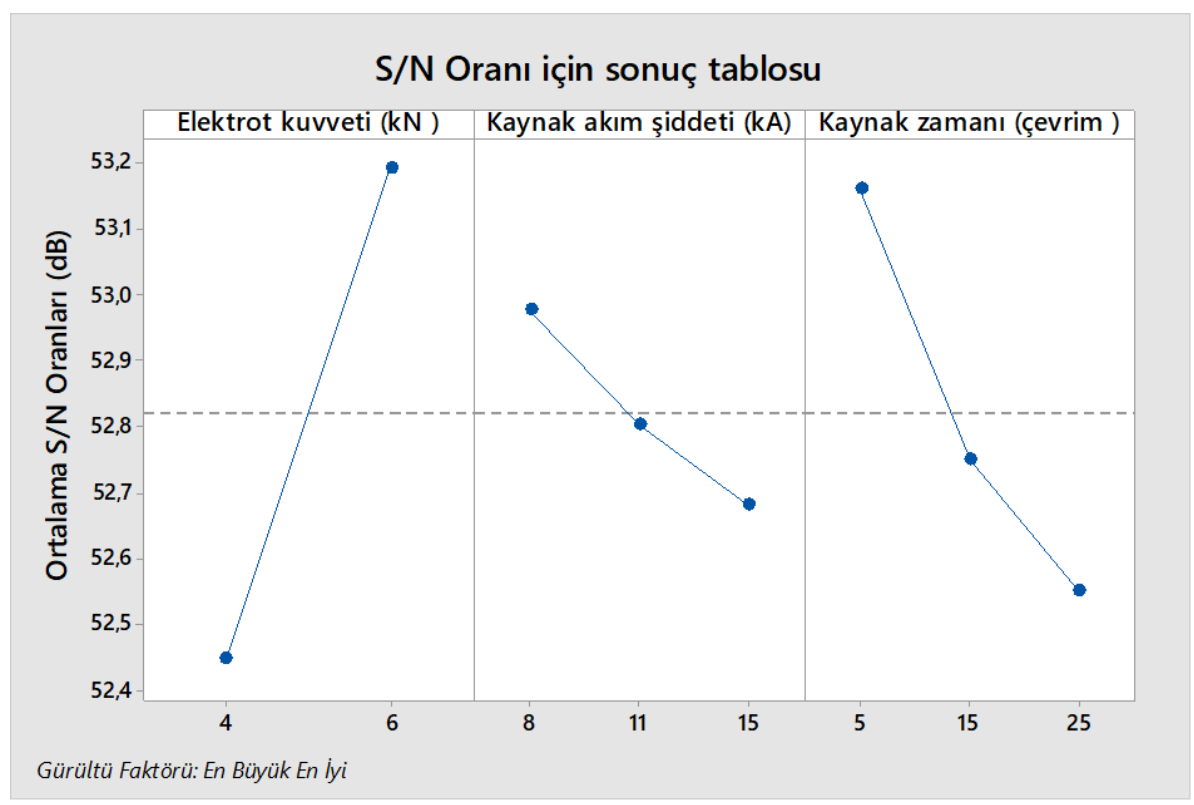

Şekil 3. S/N oranları için ana etki grafiği 


\section{B. VARYANS ANALIZİ (ANOVA)}

$\mathrm{Bu}$ deneyde kullanılan bütün kontrol faktörlerinin, birbirleri ile olan etkileşimleri, bu faktörlerin performans karakteristiğini ne kadar etkilediği, deneysel çalışmadaki parametreler farklılıkların performans karakterini ne ölçüde değiştirdiği ve bu değişim sebeplerinin belirlenebilmesi için istatiksel Varyans analizi (ANOVA) uygulanmaktadır [26]. ANOVA, deneysel verilerin analizine dayalı önemli sonuçlar sağlayan istatistiksel bir tekniktir. Bu teknik, faktörlerin etkisinin önem düzeyini veya belirli bir yanıt üzerindeki faktörler arasındaki etkileşimi ortaya çıkarmak için çok kullanışlıdır. Deneysel parametrelerin etki aralığını, değişkenliğini, faktörlerin katkılarını ve hataya oranlarını gösteren ANOVA analizi Tablo 5'de verilmiştir. ANOVA, regresyon ortalama karesi ile ortalama kare hatası arasındaki oranı belirler ve F oranı veya varyans oranı olarak adlandırır. Bu oran aynı zamanda hata teriminden kaynaklanan bir faktör ve varyansın etkisine bağlı bir orandır. F oranının hesaplanan değeri yüksekse, faktör istenen seviyede anlamlıdır. Genel olarak, F değeri arttığında, belirli parametrenin önemi ve katk1 yüzdesi de artar. ANOVA işlemi \% 95 güvenirlik ve \% 5 önem seviyelerinde uygulanmıştır. Deneyde kullanılan kontrol faktörlerin etki düzeylerinin belirlenmesinde, etki değeri en fazla olan F değeri sonuca en çok etki eden değer olarak belirlenir. Bu değerin belirlenmesinde F değeri sonuçları birbirleri ile kıyaslanmaktadır. ANOVA sonuçları incelendiğinde kaynak sertliğini etkileyen en önemli parametre \% 62.46 oranla elektrot kuvveti olmuştur. Kaynak zamanı ise \% 29.07'lik oranla elektrot kuvvetinden sonra ikinci etkili parametredir. Son olarak diğerlerine göre daha düşük etkiye sahip parametre \% 6.55 oranla kaynak akım şiddeti olarak görülmüştür. Burada, her bir değişkenin sonuçlar üzerindeki serbestlik derecesini gösteren DF değerleriyle, kareler toplamı (SS), kareler ortalaması (MS), F değerleri ve yüzde katkı oranları (PCR) görülmektedir.

Tablo 5. Sertlik Değeri S/N oranları için Varyans analizi (ANOVA) sonuçları

\begin{tabular}{lccccc}
\hline Kaplama Parametreleri & $\begin{array}{c}(\mathbf{D F}) \\
\text { Serbestlik } \\
\text { Derecesi }\end{array}$ & $\begin{array}{c}(\mathbf{S S}) \\
\text { Kareler Top. }\end{array}$ & $\begin{array}{c}\text { (MS) } \\
\text { Kareler } \\
\text { Ort. }\end{array}$ & F-Değeri & $\begin{array}{c}\text { (PCR) } \\
\text { Katkı Oranı }\end{array}$ \\
\hline Elektrot kuvveti (kN) & 1 & 6317,3 & 6317,25 & 390,84 & $\% 62,46$ \\
\hline Kaynak akım şiddeti (kA) & 2 & 662,4 & 331,19 & 20,49 & $\% 6,55$ \\
\hline Kaynak zamanı (çevrim) & 2 & 2940,0 & 1470,02 & 90,95 & $\% 29,07$ \\
\hline Hata & 12 & 194,0 & 16,16 & - & $\% 1,92$ \\
\hline Toplam & 17 & 10113,6 & & & $\% 100.00$ \\
\hline
\end{tabular}

\section{DOĞRULAMA TESTI}

Taguchi yöntemiyle yapılan optimizasyon işleminin son adımı, optimize elektrik direnç nokta kaynağı deneysel girdi seviyelerini kullanarak kaynak çekirdeği mekanik özelliklerin değişimi tahmin etme ve sonuçların karşıllaştııılmasıdır. Taguchi metodu ile hesaplanan optimum değerler yapılan deney tasarımında yer aldığ 1 için doğrulama deneyleri yapılmamıştır. Doğrulama deneyi yerine hesaplanan ve doğrulanan kaynak çekirdeği sertlik seviyelerinin deneysel sonuçları karşılaştırılması Tablo 6'da verilmiştir. Bu çalışma ile DP800HF ve $1200 \mathrm{M}$ saclarının elektrik direnç nokta kaynağ 1 , kaynak dikişi sertlik miktarının, kaynak esnasında kullanılan parametrelerin farklılaşmasıyla birlikte değiştiği Taguchi optimizasyon yöntemi kullanılarak kanıtlanmıştır. Taguchi optimizasyonunun dikiş sertliği çıktılarının performans karakteristiklerinin belirlenmesinde uygulanan basit ve güvenilir bir yöntem olduğu kanıtlanmıştır. Ayrıca Şekil 4'de Taguchi metoduyla yapılan analiz sonucu elde edilen tahmin sonuçlarının gerçek sonuçlar ile karşılaştırmalı doğrulma grafiği verilmiştir. 
Tablo 6. Doğrulama deney sonuçları

\begin{tabular}{ccc}
\hline Tahmin Edilen Sonuçlar & Deneysel Sonuçlar & Fark \\
\hline A2B1C1 & A2B1C1 & - \\
\hline Sertlik 481,821 HV & Sertlik 481,42 $\mathrm{HV}_{0.2}$ & 0.401 \\
\hline S/N 53,6876 dB & S/N 53,6505 dB & 0.0371 \\
\hline
\end{tabular}

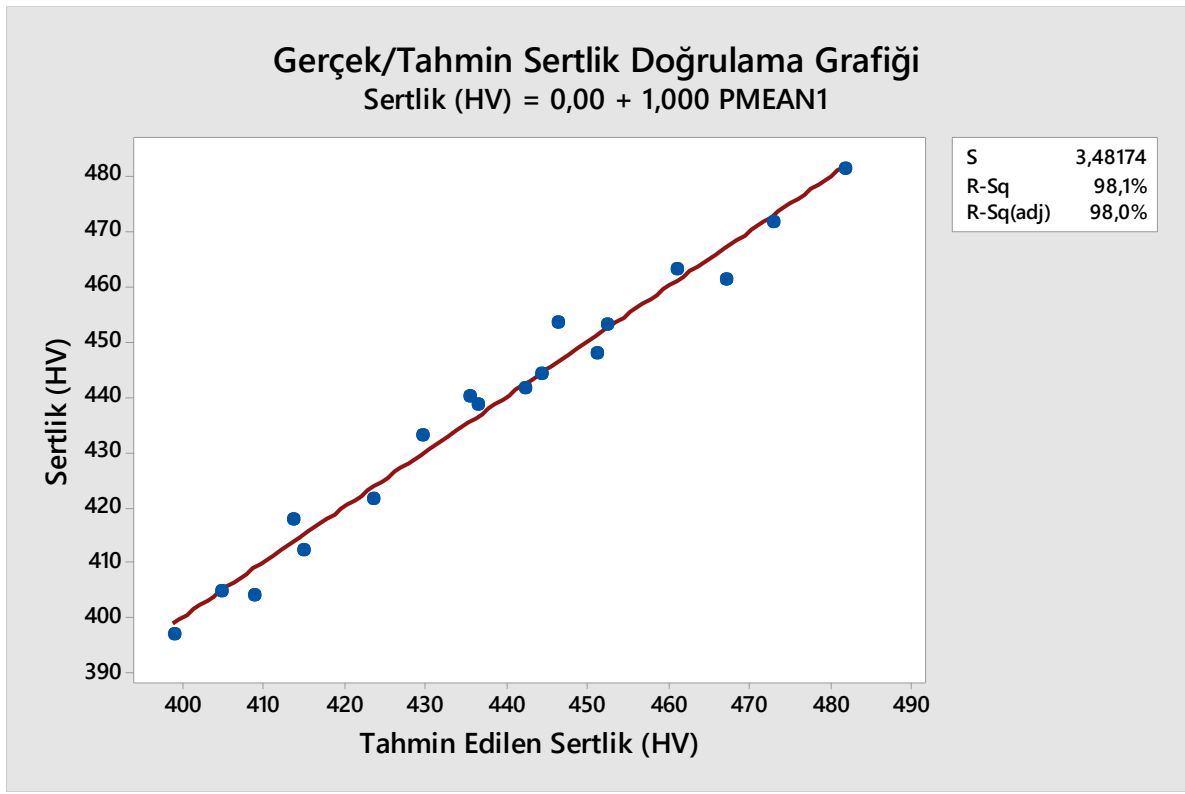

Şekil 4. Gerçek sertlik ve tahmin edilen sertlik değerleri karşılaştırma grafiği.

\section{IV.SONUC}

$\mathrm{Bu}$ çalışma kapsamında yapılan deneysel çalışma ve optimizasyon işlemi kapsamında elde edilen sonuçlar aşağıda verilmiştir.

1. DP800HF ve $1200 \mathrm{M}$ saclarının elektrik direnç nokta kaynağı ile sorunsuz bir şekilde kaynatılabildiği tespit edilmiştir.

2. Deneysel çalışmalarda, Taguchi $\mathrm{L}_{18}$ deney tasarımı ve optimizasyonu DP800HF ve $1200 \mathrm{M}$ saclarının elektrik direnç nokta kaynağı ișlemi için başarılı bir şekilde uygulanmıștır.

3. En iyi kaynak dikişi sertlik değerine, $6 \mathrm{kN}$ elektrot gücü, $8 \mathrm{kA}$ kaynak akımı değerinde ve 5 çevrim kaynak zamanında ulaşılmıştır.

4. ANOVA sonuçlarına göre, sertlik değeri üzerindeki en etkili parametrenin \% \% 62.46 oranla elektrot kuvveti olduğu, kaynak zamanının ise \% 29.07'lik oranla ikinci etkili parametre olduğu, son olarak diğerlerine göre daha düşük etkiye sahip parametre \% 6.55 oranla kaynak akım şiddeti olduğu tespit edilmiştir.

5. Optimum şartlarında gerçekleştirilen elektrik direnç nokta kaynağı sonrasında kaynak çekirdeği sertlik değeri, sırasıyla tahmin edilen ve deneysel çalışma sonucu $481.82 \mathrm{HV}_{0.2}$ ve $481,42 \mathrm{HV}_{0.2}$ olarak bulunmuştur.

TEȘEKKÜR: $\mathrm{Bu}$ çalışma Sakarya Üniversitesi Bilimsel Araştırma Projeleri tarafindan desteklenmiştir (Proje No: 2018-50-01-008).

Yazarlar ayrıca, katkılarından dolayı Prof. Dr. Uğur ÖZSARAÇ’a, laboratuvar desteğinden dolayı BORÇELIKK Ar-Ge Merkezine teşekkürlerini sunarlar. 


\section{KAYNAKLAR}

[1] J. Namukasa, S. Namagembe, and F. Nakayima, "Fuel efficiency vehicle adoption and carbon emissions in a country context," Int. J. Glob. Sustain., vol. 4, no 1, pp. 1, 2020.

[2] S. K. Khanna and X. Long, "Fatigue behavior of spot welded joints in steel sheets," in Failure Mechanisms of Advanced Welding Processes, Elsevier Ltd., 2010, pp. 65-100.

[3] S. Hassanifard, M. Zehsaz, and F. Esmaeili, "Spot weld arrangement effects on the fatigue behavior of multi-spot welded joints," J. Mech. Sci. Technol., vol. 25, no 3, pp. 647, 2011.

[4] H. T. Tran, K. Y. Kim, and H. J. Yang, "Weldability prediction of AHSS stackups using support vector machines," Int. J. Comput. Electr. Eng., vol. 6, no 3, pp. 207-210, 2014.

[5] D. Dong, Y. Liu, Y. Yang, J. Li, M. Ma, and T. Jiang, "Microstructure and dynamic tensile behavior of DP600 dual phase steel joint by laser welding," Mater. Sci. Eng. A, no. 594, pp. 17-25, 2014.

[6] M. Marya and X. Q. Gayden, "Development of requirements for resistance spot welding dualphase (DP600) steels part 2: Statistical analyses and process maps," Weld. J. (Miami, Fla), vol. 84, no. $12,2005$.

[7] J. Górka, A. Ozgowicz, and K. Matusek, "Robotic spot welding of DOCOL 1200M steel," Weld. Technol. Rev., vol. 91, no 4, pp. 33-38, 2019.

[8] V. Onar and S. Aslanlar, "Welding time effect of welding joints in micro alloyed and TRIP 800 steels in resistance spot welding," Acta Phys. Pol. A, vol. 131, no. 3, pp. 389-391, 2017.

[9] S. Aslanlar, "The effect of nucleus size on mechanical properties in electrical resistance spot welding of sheets used in automotive industry," Mater. Des., vol. 27, no. 2, pp. 125-131, 2006.

[10] S. K. Panda, J. Li, V. H. B. Hernandez, Y. Zhou, and F. Goodwin, "Effect of weld location, orientation, and strain path on forming behavior of AHSS tailor welded blanks," J. Eng. Mater. Technol. Trans. ASME, vol. 132, no. 4, pp. 1-11, 2010.

[11] C.-W. Ji, I. Jo, H. Lee, I.-D. Choi, Y. do Kim, and Y.-D. Park, "Effects of surface coating on weld growth of resistance spot-welded hot-stamped boron steels," J. Mech. Sci. Technol., vol. 28, no 11, pp. 4761-4769, 2014.

[12] S. Smith, N. J. den Uijl, T. Okada, T. van der Veldt, M. Uchihara, and K. Fukui, "The Effect of Ageing on the spot weld strength of AHSS and the consequences for testing procedures," Weld. World, vol. 54, no. 1, pp. R12-R26, 2010.

[13] Y. Li, Z. Lin, Q. Shen, and X. Lai, "Numerical analysis of transport phenomena in resistance spot welding process," J. Manuf. Sci. Eng., vol. 133, no. 3, 2011.

[14] M. Pouranvari and S. P. H. Marashi, "Critical review of automotive steels spot welding: Process, structure and properties," Sci. Technol. Weld. Join., vol. 18, no. 5, pp. 361-403, 2013.

[15] X. Wang, K. Zhou, and S. Shen, "Intelligent parameters measurement of electrical structure of medium frequency DC resistance spot welding system," Measurement, vol. 171, no. 108795, 2021.

[16] H. Lee and J. Yu, "Development of fuzzy controller for inverter DC resistance spot welding using system identification," J. Mech. Sci. Technol., vol. 31, no. 8, pp. 3961-3968, 2017. 
[17] J. Černelič, R. Brezovnik, J. Ritonja, D. Dolinar, and M. Petrun, "Optimal operating point of medium frequency resistance spot welding systems," 2017 IEEE 26th International Symposium on Industrial Electronics (ISIE), 2017, pp. 2131-2137.

[18] K. Zhou ve P. Yao, "Review of Application of the electrical structure in resistance spot welding," IEEE Access, vol. 5, pp. 25741-25749, 2017.

[19] K. Zhou and L. Cai, "Online measuring power factor in AC resistance spot welding," IEEE Trans. Ind. Electron., vol. 61, no 1, pp. 575-582, 2014.

[20] M. R. Rawal, R. R. Kolhapure, S. S. Sutar, and V. D. Shinde, "Optimization of resistance spot welding of 304 steel using GRA,” Int. J. Comput. Eng. Res. Trends, vol. 3, no. 9, pp. 492-499, 2016.

[21] U. Eşme, "Application of taguchi method for the optimization of resistance spot welding process," Arab. J. Sci. Eng., vol. 34, no. 2 B, pp. 519-528, 2009.

[22] R. K. Verma, P. K. Kharwar, A. K. Mondal, K. Abhishek, and J. Kumar, "Exploration of MOORA based hybrid Taguchi Method for Multi-response Optimization-A case study BT Advances in Mechanical Engineering," in Advances in Mechanical Engineering Select Proceedings of ICRIDME 2018, B. B. Biswal, B. K. Sarkar, and P. Mahanta, Eds. Singapore: Springer Singapore, 2020, pp. 515-525.

[23] A. G. Thakur and V. M. Nandedkar, "Optimization of the resistance spot welding process of galvanized steel sheet using the taguchi method," Arab. J. Sci. Eng., vol. 39, no. 2, pp. 1171-1176, 2014.

[24] Y. Luo, J. Liu, H. Xu, C. Xiong, and L. Liu, "Regression modeling and process analysis of resistance spot welding on galvanized steel sheet," Mater. Des., vol. 30, no. 7, pp. 2547-2555, 2009.

[25] M. Vural and A. Akkus, "On the resistance spot weldability of galvanized interstitial free steel sheets with austenitic stainless steel sheets," J. Mater. Process. Technol., vol. 153-154, pp. 1-6, 2004.

[26] H. Kır ve S. Apay, "Elektrolitik yöntemle sert krom kaplanan yapı çeliğinde kaplama parametrelerinin taguchi metodu ile optimizasyonu," Gümüşhane Üniversitesi Fen Bilim. Enstitüsü Derg., c. 10, ss. 7-14, 2020.

[27] N. Masmiati and A. A. D. Sarhan, "Optimizing cutting parameters in inclined end milling for minimum surface residual stress - Taguchi approach," Measurement, vol. 60, pp. 267-275, 2015. 